\title{
Selection of patients for paediatric ambulatory surgery*
}

\author{
Raafat S. Hannallah, MD \\ Department of Anesthesiology and Pediatrics, \\ Children's National Medicine Center and George Wash- \\ ington University Medicine Center, Washington, D.C.
}

The criteria for selecting patients and procedures for paediatric ambulatory surgery vary among institutions. They are usually influenced by the condition of the patient, the attitude of the parents, the type of surgical procedure, and any special considerations for anaesthetic management and recovery. ${ }^{1}$

\section{The patient}

The child should be in good health or any systemic disease he or she has must be under good control (ASA physical status I and II). Some anaesthetists may accept ASA physical status III patients whose medical condition is well controlled. Many children with chronic diseases benefit substantially from outpatient treatment. Physically handicapped, psychologically disturbed, or mentally retarded children benefit from the lack of separation and continued support of a parent or guardian that is usually fostered in outpatient facilities.

\section{Special problems}

\section{THE CHILD WITH A RUNNY NOSE}

A child who presents with a runny nose may have either a completely benign, noninfectious condition, e.g., seasonal or vasomotor rhinitis, in which case elective surgery may safely be performed, or the runny nose may be a prodrome to, or actually be, an infectious process, in which case elective surgery should be postponed. ${ }^{2}$ Since probably $20 \%$ to $30 \%$ of all children have a runny nose for a considerable part of the year, every child with a runny nose must be evaluated on an individual basis.

The preanaesthetic assessment of these patients consists of obtaining a complete history, performing a physical examination, and examining certain laboratory

*This article is excerpted from a more extensive discussion that appears in Wetchler BV (Ed.). Anaesthesia for Ambulatory Surgery, 2nd ed. Philadelphia: JB Lippincott Co, 1991. data. Early in the clinical course, the history will be the most important single factor in the differential diagnosis. Specifically, allergic problems should be actively sought. Parents are usually well aware and can tell whether their child's runny nose is "the usual runny nose" or something different that may require cancellation of elective surgery. The physical examination is not always conclusive. Normal findings may be present during the early part of an infectious process. Chronic allergic rhinitis, on the other hand, may be associated with local infections within the nasopharynx resulting in purulent nasal discharge. A white blood cell count $\geq 12,000$ to $15,000 \cdot \mathrm{mm}^{-3}$ with a shift to the left suggests an infectious process.

If surgery is postponed because of the presence of simple nasopharyngitis, it can be usually re-scheduled in 1-2 wk. If a flu-like syndrome that involves both the upper and lower respiratory tract is present, the surgery should be postponed for at least a month following resolution of symptoms.

A common situation that poses a difficult decision is that of a child with a runny nose presenting for relatively brief or low-risk procedures such as the insertion of ventilation tubes for chronic serous otitis media. Many such children make multiple trips to the hospital for ventilation tubes, but the procedures are cancelled because of a runny nose. Many anaesthetists are willing to proceed with this group of patients, ${ }^{2-4}$ and some have reported no increase in perioperative complications associated with uncomplicated URIs. ${ }^{3,4}$ Because some of these children may be at increased risk of developing transient postoperative hypoxaemia, they should be given supplemental oxygen and/or have their oxygen saturation monitored during transport and in the postanaesthesia care unit (PACU). ${ }^{5}$

\section{THE EX-PREMIE}

The premature infant is unsuitable for ambulatory surgery because of potential immaturity of temperature control, respiratory centre, and gag reflexes. Recent studies have reported perioperative complications such as apnoea even in the absence of a history of respiratory distress syndrome.

In a retrospective chart review of healthy infants undergoing herniorrhaphy, Steward reported that $12 \%$ of preterm infants had prolonged apnoea during and up to 12 $\mathrm{hr}$ after anaesthesia. ${ }^{6}$ In the prospective study by Liu and coworkers, six infants with a history of apnoea and a conceptual age below $46 \mathrm{wk}$ had prolonged apnoea after anaesthesia and surgery. ${ }^{7}$ Seven infants who had a preoperative history of apnoea but a conceptual age of 46 to $80 \mathrm{wk}$ did not have apnoea postoperatively. A large number of patients in this study required mechanical ventilation for other, pre-existing conditions (e.g., brain damage), and therefore, the true incidence of apnoea that 
is precipitated by anaesthesia and surgery in this subgroup remains unknown.

In a study of 86 otherwise healthy infants of less than 12 mth postnatal age undergoing general anaesthesia for herniorrhaphy, Welborn and coworkers found no incidents of apnoea or periodic breathing with bradycardia on postoperative pneumograms, even in patients who had a history of preanaesthetic apnoea and who were being monitored for apnoea at home. ${ }^{8}$ Periodic breathing without bradycardia, however, was found in 14 of 38 preterm infants during the postoperative period. Periodic breathing occurred as late as five hours after surgery and was more frequent the more immature the baby. Apnoea and/or periodic breathing did not occur in former premature infants whose conceptual age was more than 44 weeks and who were without any major systemic disease at the time of surgery.

In a later study, however, Welborn reported a $73 \%$ incidence of postoperative prolonged apnoea with bradycardia in a similar group of infants whose conceptual age ranged between 35 to 44 weeks. ${ }^{9}$ In still another prospective study using pneumography, Kurth and coworkers observed a $37 \%$ incidence of postanaesthetic prolonged apnoea limited to 47 former preterm infants whose conceptual ages varied from $32 \mathrm{wk}$ to as old as $55 \mathrm{wk} .^{10}$ These authors also demonstrated that the initial episode of apnoea could occur as late as 12 ra after anaesthesia

Although the sum total of cases reported in the literature to date is approximately 300 , no one study has a large series of ASA physical status I or II patients undergoing the same operative procedures with the same anaesthetic technique. Many of the data are derived from retrospective reviews of complications or from patients with preexisting disease who underwent complex surgical procedures. Therefore, it is difficult to make definitive statements that specifically apply to outpatients. Moreover, the importance of apnoeic episodes that are long enough to result in bradycardia and arterial oxygen desaturation but eventually self-correct before cardiorespiratory arrest develops remains enigmatic. While one may argue that the spontaneous return of respiration is the most likely outcome in these infants, potential deleterious hypoxic-ischaemic effects on the brain or even a relationship to SIDS in many children has been suggested. Failure to detect and treat breathing irregularities in these highrisk infants may increase the likelihood of sudden death. The bottom line is that a history of prematurity is a red flag that means these infants must be observed very carefully for episodes of postoperative apnoea.

The age at which the premature infant attains physiological maturity and no longer presents an increased risk must be considered individually, with attention given to growth and development, persistent problems during feeding, time to recovery from upper respiratory infections, apnoeic history, and presence or absence of metabolic, endocrine, neurological, or cardiac disorders.

It is generally considered that the infants at greatest risk are those younger than $46 \mathrm{wk}$ post-conceptual age with a preoperative history of apnoea. Obviously, there must be a middle ground between the conservative $60 \mathrm{wk}$ recommended by Kurth and coworkers and the recommendations by Liu et al. and Welborn et al. of 44 to $46 \mathrm{wk}$. It appears that, as the child matures, the tendency toward apnoea greatly diminishes, but no one knows the age at which all babies may be anaesthetized safely on an outpatient basis. Therefore, until more extensive, meticulous, prospective studies are carried out, it seems prudent to admit to the hospital all ex-premature infants of less than 50 wk post-conceptual age so that they may be monitored postoperatively for possible apnoea, bradycardia, and oxygen desaturation. It is also appropriate to individualize this decision and, when in doubt, to err on the side of conservatism. If the infant has bronchopulmonary dysplasia (BPD), this period should be extended for as long as the infant is symptomatic. Should any questions arise, inpatient care is recommended.

Two recent reports by Welborn et al. suggest that the use of a single intravenous dose of caffeine at the beginning of surgery may be effective in the control of postanaesthetic apnoea in former premature infants. ${ }^{9,11}$ When a $5 \mathrm{mg} \cdot \mathrm{kg}^{-1}$ dose was used, no infant developed prolonged apnoea with bradycardia. However, complete abolition of periodic breathing, was not seen. In a later study, the authors reported that a $10 \mathrm{mg} \cdot \mathrm{kg}^{-1}$ dose of caffeine was effective in the control of all types of apnoea in these infants. ${ }^{11}$ It is still recommended that until more extensive experience with this approach is available, all infants at risk should be monitored for apnoea and/or bradycardia following anaesthesia.

\section{THE CHILD WITH HEART MURMUR}

A common problem in paediatric outpatient anaesthesia is the child in whom a previously undiagnosed cardiac murmur is first heard during the preanaesthetic examination. Even if the child is asymptomatic, it is imperative that the cause of the murmur be correctly diagnosed before anaesthesia and surgery. A recent study has shown that a paediatric cardiologist may be the only person who can confirm that a murmur is innocent by physical examination alone. ${ }^{12}$ The grid shown in the Table serves as a guide as to when a cardiology consultation is needed before proceeding with surgery. ${ }^{1}$

A child with a confirmed cardiac lesion may not require specific preoperative cardiac therapy or even a modification in the selection of anaesthetic agents and technique, but he or she usually needs antibiotic prophylaxis to 
TABLE The Child with a heart murmur

\begin{tabular}{|c|c|c|c|c}
\hline $\begin{array}{l}\text { Clinical } \\
\text { diagnosis }\end{array}$ & $\begin{array}{l}\text { No } \\
\text { heart } \\
\text { disease }\end{array}$ & \multicolumn{2}{l|}{$\begin{array}{l}\text { Possible } \\
\text { heart } \\
\text { disease }\end{array}$} & \multicolumn{2}{l|}{$\begin{array}{l}\text { Definite } \\
\text { heart } \\
\text { disease }\end{array}$} \\
\hline Anaesthetist & Yes & Yes & No & Yes \\
\hline Paediatrician & Yes & No & Yes & Yes \\
\hline Cardiology consult? & No & \multicolumn{2}{|c|}{ Yes } & Yes \\
\hline
\end{tabular}

prevent subacute bacterial endocarditis. To prevent delay and cancellations, surgeons and paediatricians must be told to have a child with a murmur fully evaluated before the day of surgery. The specific diagnosis, and recommendations for therapy, if any, should be known by the anaesthetist in advance. For quick reference, every department of anaesthesia should have available the most recent American Heart Association's guidelines for prevention of bacterial endocarditis. ${ }^{13}$

\section{The parent}

In the past, the choice of outpatient care has been largely influenced by parents' wishes and the experiences of friends and family. Third-party payers and government regulators are now increasingly reluctant to comply with parents' demands for hospitalization of a healthy child who is having a relatively minor superficial operation. Parents of paediatric outpatients, however, should be capable of understanding and willing to follow specific instructions related to ambulatory surgery. In most cases, it is up to the physician to educate them and make them feel secure and comfortable.

\section{The procedure}

The planned surgical procedure should be brief and should be associated with only minimal bleeding and minor physiological derangements. Most experts believe that almost any operation that does not require a major intervention into the cranial vault, abdomen, or thorax can be considered. Superficial procedures are selected most often. Septic cases are rarely considered because of the need for separate facilities in the recovery area.

The five most frequently performed operations at Children's National Medical Centre (CNMC) Day Surgery Unit during the past two years were herniorrhaphy, myringotomy, adenoidectomy with or without myringotomy, circumcision, and eye-muscle surgery.

Because of the risk of haemorrhage, there is a continuing debate as to the advisability of performing tonsillectomy with or without adenoidectomy as an outpatient procedure. This procedure is not currently performed on an ambulatory basis at CNMC. In 1968, however, Chiang and associates reported 40,000 outpatient tonsillectomies and adenoidectomies (T \& As) without death. ${ }^{14}$ In order to decrease the risk of haemorrhage, they emphasized careful selection of cases and preoperative evaluation to eliminate patients with bleeding tendencies and cardiopulmonary disease. Also, no "allergic" patient was operated on during the pollen season, and no operation was performed until four to five weeks after an attack of acute tonsillitis.

More recently, Maniglia and coworkers reported a series of 1428 cases of adenotonsillectomies performed on outpatients. ${ }^{15}$ Two cases $(0.14 \%)$ of immediate (within $24 \mathrm{hr}$ ) bleeding and two late (after $24 \mathrm{hr}$ ) episodes occurred. The two incidents of immediate bleeding occurred within the first hours following the surgical procedure. The authors concluded that outpatient adenotonsillectomy is safe and cost-effective and that there was little benefit in keeping patients in the hospital more than a few hours after surgery.

\section{References}

1 Hannallah RS, Epstein BS. Management of the pediatric patient: In: Wetchler BV (Ed.). Anesthesia for Ambulatory Surgery, 2nd ed. Philadelphia: J.B. Lippincott Company, 1991.

2 Berry FA. The child with the runny nose. In: Berry FA (Ed.). Anesthetic Management of Difficult and Routine Pediatric Patients. New York: Churchill-Livingstone, 1986; 349-67.

3 Tait $A R$, Knight PR. Intraoperative respiratory complications in patients with upper respiratory tract infections. Can J Anaesth 1987; 34: 300-3.

4 Tait AR, Knight $P R$. The effect of general anesthesia on upper respiratory tract infections in children. Anesthesiology 1987; 67: 930-5.

5 DeSoto H, Patel RI, Soliman IE, Hannallah RS. Changes in oxygen saturation following general anesthesia in children with upper respiratory infection signs and symptoms undergoing otolaryngological procedures. Anesthesiology 1988; 68: 276.

6 Steward DJ. Pre-term infants are more prone to complications following minor surgery than are term infants. Anesthesiology 1982; 56: 304-6.

7 Liu LMP, Coté CJ, Goudsouzian NG et al. Lifethreatening apnoea in infants recovering from anesthesia. Anesthesiology 1983; 59: 506-10.

8 Welborn LG, Ramirez N, Oh TH et al. Postanesthetic apnoea and periodic breathing in infants. Anesthesiology 1986; 65: 657-61.

9 Welborn LG, DeSoto H, Hannallah RS et al. The use of caffeine in the control of post-anesthetic apnoea in former premature infants. Anesthesiology 1988; 68: $796-8$.

10 Kurth CD, Spitzer AR, Broennle AM, Downes JJ. Postop- 
erative apnoea in preterm infants. Anesthesiology 1987 ; 66: 483-8.

11 Welborn LG, Hannallah RS, Fink R, Ruttimann UE, Hicks $J M$. High-dose caffeine suppresses postoperative apnoea in former preterm infants. Anesthesiology 1989; 71: 347-9.

12 Newburger JW, Rosenthal A, Williams RG, et al. Noninvasive tests in the initial evaluation of heart murmurs in children. N Engl J Med 1983; 308: 61-3.

13 American Heart Association special report. Prevention of bacterial endocarditis. JAMA 1990; 264: 2919-22.

14 Chiang $T M$, Suskis AE, Ross DE. Tonsillectomy performed on an outpatient basis: report of a series of 40,000 cases performed without a death. Arch Otolaryngol Head Neck Surg 1968: 88: 307-9.

15 Maniglia AJ, Kushner H, Cozzi L. Adenotonsillectomy: a safe outpatient procedure. Arch Otolaryngol Head Neck Surg 1989; 115: 92-5.

\section{What are the problems in the recovery room?}

\author{
Bernard V. Wetchler MD \\ Division of Anesthesia, University of Illinois College of \\ Medicine at Peoria, Peoria, Illinois
}

Every outpatient facility must be able to limit the problems that cause unanticipated admissions to the hospital and they must have practical discharge criteria if patients are to go home in a timely fashion following outpatient surgery. As anaesthetists we have little or no control over the complications of surgery that cause admission to the hospital, but we can play a major role in limiting admissions due to pain, emesis and croup.

\section{Pain}

Postoperative pain control should be started intraoperatively by supplementing intravenous or inhalation anaesthesia with short-acting narcotic analgesics (alfentanil, fentanyl, sufentanil), a nonsteroidal anti-inflammatory drug (ketorolac) or local/ regional block. By making appropriate use of narcotic analgesics or local/regional block intraoperatively, awakening will be smoother and discharge home will occur sooner.

Postsurgical pain must be treated quickly and effectively. Medications given in the recovery room (RR) should be monitored closely and given in small, immediately
TABLE Paediatric recovery room pain control

\begin{tabular}{|c|c|c|}
\hline Drug & Dose & Route \\
\hline Fentanyl & $0.35-0.70 \mu \mathrm{g} \cdot \mathrm{kg}^{-1}$ & iv \\
\hline Alfentanil & $2-4 \mu \mathrm{g} \cdot \mathrm{kg}^{-1}$ & $i v$ \\
\hline Acetaminophen & $60 \mathrm{mg} \cdot \mathrm{yr}^{-1}$ & po \\
\hline $\begin{array}{l}\text { Acetaminophen } 120 \mathrm{mg} \text {, } \\
\text { codeine } 12 \mathrm{mg} \text {, elixir } 5 \mathrm{ml}\end{array}$ & $5-10 \mathrm{ml}$ & po \\
\hline Meperidine & $0.5 \mathrm{mg} \cdot \mathrm{kg}^{-1}$ & $i m$ \\
\hline Codeine & $1-1.5 \mathrm{mg} \cdot \mathrm{kg}^{-1}$ & im \\
\hline
\end{tabular}

effective intravenous doses. Intramuscular injection for pain control in the RR is probably more a custom than a thoroughly considered process.

At Methodist Ambulatory SurgiCare pain in both adults and children is managed with a short-acting narcotic analgesic (fentanyl, alfentanil). Fentanyl $12.5 \mu \mathrm{g}$ iv every five minutes up to a total dose of $50-75 \mu \mathrm{g}$ or alfentanil $50-75 \mu \mathrm{g}$ iv every two to three minutes up to a total dose of $200-300 \mu \mathrm{g}$ has proved to be very effective for the adult. Pain control for the paediatric patient will be found in the Table. Reuniting child with parent as soon as possible following entry into the RR helps to differentiate between crying from fright or crying from pain.

A decrease in pain, analgesic requirement, $R R$ sideeffects, earlier home readiness, and more rapid return to normal activity can be achieved by combining many simple (sensory) nerve blocks with intravenous or inhalation anaesthesia.

When the ilioinguinal and iliohypogastric nerves were infiltrated with bupivacaine during paediatric herniorrhaphy less codeine im was administered in the RR, less acetaminophen was required at home and a higher activity level was noted over the $\mathbf{4 8} \mathrm{hr}$ following surgery than in a control group. ${ }^{1}$ Lidocaine aerosolized into the surgical wound before closure in adult patients undergoing inguinal herniorrhaphy reduced pain after a single administration compared with untreated patients. ${ }^{2}$

Circumcision is a procedure that lends itself to local or regional supplementation: dorsal nerve block; topical anaesthesia (lidocaine spray, 10-20 mg of $10 \%$; lidocaine jelly, 0.5-1 ml of 2\%: lidocaine ointment, $0.5-1 \mathrm{ml}$ of $5 \%$ ); subcutaneous ring block with $0.25 \%$ bupivacaine provide effective pain control. ${ }^{3-5}$

Caudal block supplementation has been utilized to limit paediatric patients' postsurgical pain (circumcision, herniorrhaphy, hypospadias, orchiopexy). Whenever a caudal is administered for analgesia, care must be taken that motor strength is not compromised in an attempt to obtain pain control. There does not appear to be any advantage to using more concentrated solutions than $0.25 \%$ bupivacaine containing epinephrine $1: 200,000$. Wolf and coworkers noted that $0.0625 \%$ bupivacaine was ineffective for caudal analgesia. ${ }^{6}$ However, in a volume 